\title{
The Non-Monetary Side of the Global Disinflation*
}

\author{
Gregor Schwerhoff ${ }^{\dagger} \quad$ Mouhamadou Sy ${ }^{\ddagger}$
}

October 2010

\begin{abstract}
The dramatic decline in inflation across the world over the last 20 years has been largely credited to improved monetary policy. The universal nature of the phenomenon and its simultaneity with globalization however indicate that there might also be a "real" side to it. We build a model based on Melitz (2003) in which falling transport cost lead to greater openness, higher productivity and lower inflation. Following a decline in transport cost openness increases and firm selection eliminates the least productive domestic firms. The consequent increase in average productivity leads to falling relative prices for goods. A cash-in-advance constraint allows to analyse how falling relative prices can lead to lower inflation. Using a dataset of macroeconomic variables for 107 countries from all world regions we are able to show that openness-induced productivity growth leads to a significant decline in inflation world wide.
\end{abstract}

JEL classification: F15, F41, E31

Keywords: Globalization, openness, productivity, disinflation

${ }^{*}$ The authors wish to thank Vasco Carvalho, Daniel Cohen, Mathieu Couttenier, Martin Hellwig, Jean Imbs, Alberto Martin, Romain Rancière, Hamidreza Tabarraei and Mirko Wiederholt for helpful comments. This research was conducted while the authors were visiting UPF, Barcelona.

${ }^{\dagger}$ Bonn Graduate School of Economics (BGSE): Adenauerallee 24, 53113 Bonn, Germany. Email: gschwerh@uni-bonn.de

${ }^{\ddagger}$ Paris School of Economics (PSE): 48 Boulevard Jourdan, 75014 Paris, France. Email: sy@pse.ens.fr. I gratefully acknowledge financial support from the Region Ile-de-France. 


\title{
1 Introduction
}

\author{
The fact that inflation has fallen everywhere - even in countries with weak institutions, \\ unstable political systems, thinly staffed central banks, etc. - invites us to open our minds to \\ the possibility that other factors have also been significant. Kenneth S. Rogoff, (2003)
}

During the early 1990s the world wide patterns of openness to trade and inflation have changed dramatically. All regions of the world increased openness to trade strongly bringing the world average from $39 \%$ in 1990 to $54 \%$ in 2005. In a parallel development, inflation saw an even more dramatic change, coming down from a world average of $26 \%$ in 1990 to only $3.8 \%$ in 2005 . As Rogoff (2003) points out a number of possible approaches can explain this fall in inflation, among them improved monetary policy, technological development and globalization. We will argue in this paper that globalization in the form of increasing openness to trade is a driving force of falling inflation.

The increase in trade has ultimately been triggered by a reduction in obstacles to trade, consisting of political barriers and cost for physical transport. They have reduced through lower tariffs and free trade agreements on the political side and technological progress on the side of physical transport cost. Aghion et al. (2008) for example reports a fall in tariff rates in India from 133 in 1990 to 48 in 1997.

We define openness as imports plus exports over GDP. The reallocation of production through reduced transport cost has an obvious effect on openness thus defined. Since consumers have a taste for variety, they consume available products from abroad. And as falling transport cost allows more foreign producers to export, imports and exports increase.

Transport cost also affect competition. When they fall, more and more firms are able to profitably export their products to other countries. The empirical and theoretical literature (Syverson (2004), Bernard et al. (2003), Bernard et al. (2006), Pavcnik (2002)) shows that this increase in competition forces the least productive firms out of the market and production is reallocated towards more productive firms. Industries, even if narrowly defined show a large variety of productivity. When competition increases, the least productive firms can no longer make positive profits and have to quit the market.

Inflation is affected via productivity. As more trade increases competition, some firms that could operate profitably in a more closed market, are no longer able to do so. They have to stop production and leave the market. As a consequence, average productivity in 
the economy increases. This in turn leads to lower average prices, which reduces inflation. In addition, more open countries consume more goods from abroad, which reduces average consumption prices since only the most productive foreign firms export.

Productivity and its reaction to transport cost play a vital role in this concept. So we use the framework of Melitz (2003), where productivity is endogenously determined. We modify it to analyze the interaction of productivity with openness and inflation.

Romer (1993) finds that openness and inflation are negatively related. He argues that the reason for this is the higher cost of monetary expansion, because of the real exchange rate depreciation. Rogoff (2003) also finds the incentive structure for the central bank to provide the link between globalization and disinflation. His argument however is that more competition from abroad makes prices and wages more flexible. On the other hand he notes "The fact that inflation has fallen everywhere - even in countries with weak institutions, unstable political systems, thinly staffed central banks, etc. - invites us to open our minds to the possibility that other factors have also been significant."

Chen et al. (2004) investigate the effect of increased trade on prices, productivity and markups in the EU. They find that for the period 1988 to 2000 increased openness in the EU reduced manufacturing prices by $2.3 \%$, increased productivity by $11 \%$, reduced markups by $1.6 \%$ and, assuming unchanged monetary policy, reduced inflation by up to $0.14 \%$ per year. Similarly, Chen et al. (2009) estimates a version of Ottaviano and Melitz (2008) and obtain directly estimable equations. So these papers find the same qualitative results, but focus on one world region, the European Union, for which they are able to use disaggregated data on the manufacturing sectors.

Using a structural model of inflation Guerrieri et al. (2009) estimate a New Keynesian Phillips curve where markups react to foreign competition. They analyze US data and find that foreign competition has lowered domestic goods inflation in the US about 1 percentage point over the 2000 to 2006 period. Finally, there are papers such as Auer and Fischer (2010) which quantify the effect of low-price imports on the inflation of individual countries.

So while these papers explore the monetary side as well as productivity, markups and import prices on the real side as causes of disinflation, none of the studies above attempts to answer to Rogoff's challenge to explain disinflation worldwide, including countries with "thinly staffed central banks". This paper links productivity and a precise measure of globalization to inflation, using a macroeconomic dataset of 107 countries from all world regions. It attempts 
to shed light on the concentration of the cross-country distribution of inflation rates around 3 percent, in other words on the global dimension of global disinflation.

We will illustrate our thesis of a fundamental and important link between trade globalization and global disinflation in three steps. Section 2 will give an intuitive approach, illustrating the astounding comovement between openness and inflation and its context graphically as well as in descriptive statistics. Section 3 provides the theory which informes us on why we should expect a strong link between openness and inflation. Section 4 explores causility with a detailed econometric analysis. Section 5 concludes.

\section{Descriptive Evidence}

This section sets out to illustrate the case for an important role of openness on inflation graphically. It aims to give a first impression and an intuition before we will continue to establish theoretical links and causality in the following.

One of the most important manifestations of globalization is trade openness. Since the early 1990s, the trend towards more trade has been rapid. As Table 1 illustrates, openness as measured as (import plus export)/GDP has increased by almost 16 percentage points in the 15 years to 2005 , reaching $54 \%$. This trend has been truly global as it occured in the developed and devoloping world, climbing steeply in every single continent.

Table 1: Openness, measured as (Import + Export)/GDP

\begin{tabular}{ccccccc}
\hline \hline Year & World & Developed & Developing & Asia & Africa & Latin America \\
\hline 1990 & 38.30 & 34.90 & 39.41 & 47.22 & 51.76 & 31.52 \\
1995 & 42.04 & 37.35 & 47.29 & 58.67 & 57.61 & 37.33 \\
2000 & 49.10 & 44.87 & 52.97 & 66.85 & 63.20 & 41.28 \\
2005 & 54.04 & 46.41 & 62.85 & 86.86 & 66.64 & 46.13 \\
\hline \hline
\end{tabular}

Source: World Development Indicators, authors calculation

As the sum of imports and exports has climbed quickly, the distribution of imports and exports has diverged equally quickly. Open borders have allowed countries to have unbalanced current accounts, a possibility that was used increasingly. Figure 1 shows the cross country distribution of current accounts around the world. In 1980 we still find a sharp peak of 
current accounts around zero. In the following 10 years, not much changed, so that roughly the same pattern can be found in 1990. But as globalization takes hold during the 1990s, a strong trend towards a more dispersed distribution emerges. The peak declines significantly and more mass moves to the tails: Current accounts are increasingly unbalanced, with more countries running either large surplusses or big deficits. The trend continues well into the 2000 s, as ever more mass wanders to the tails.

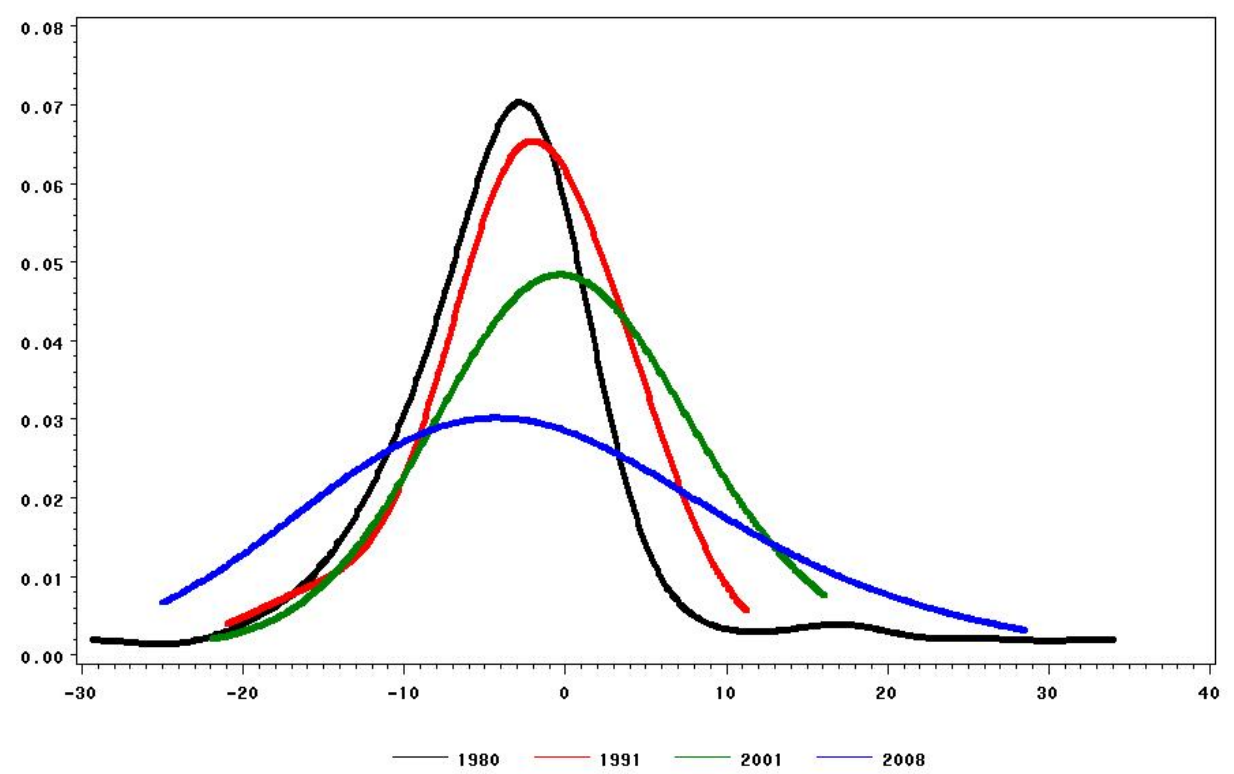

Figure 1: World cross country distribution of current accounts. Note: These curves are the Kernel density plots of current account balance of countries
with no missing data between 1980 and 2008 in the International Monetary Fund
Database, World Economic Outlook (WEO, IMF). Data in the vertical axis are
frequencies in unit and those in the horizontal axis are current account balances over
gdp in percent.
Source: WEO, authors calculation.

A mirror image of this trend is found for inflation, see Table 2. World wide, inflation has fallen from more than $26 \%$ in 1990 to a mere $3.8 \%$ in 2005, with most of this drop having occured in the 1990s. Note that for calculating the average, inflation in each country is weighted by the country's GDP. In developed countries it was already low in 1990 and has fallen reliably below $3 \%$ since 1995. Impressive advances have been made in developing countries, where inflation has come down from very high numbers to single-digit values. 
Table 2: Inflation (\% per year)

\begin{tabular}{ccccccc}
\hline \hline & & & & & & \\
Year & World & Developed & Developing & Asia & Africa & Latin America \\
\hline 1990 & 26.10 & 5.16 & 74.27 & 6.13 & 13.81 & $474.14^{*}$ \\
1995 & 14.61 & 2.63 & 39.56 & 12.62 & 36.25 & 41.34 \\
2000 & 4.55 & 2.24 & 8.61 & 1.93 & 11.78 & 7.84 \\
2005 & 3.76 & 2.22 & 5.86 & 3.80 & 7.11 & 6.19 \\
\hline \hline
\end{tabular}

Sources: World Economic Outlook, authors calculation.

* This figure excludes Argentina and Brazil. Including these two countries gives an even higher value: 1805.24

The disappearance of hyperinflations, especially in Latin America, must of course be credited to improved monetary policy. Table 2 therefore reflects two effects on a descriptive basis, which are disentangled theoretically in the next chapter: The disappearance of very high values of inflation on the one hand and the universality of the trend to lower inflation on the other hand.

This trend towards lower inflation has given rise to an opposite movement to that found in Figure 1 for openness: The distribution of inflation levels around the world has become increasingly concentrated, see Figure 2, In 1980 the peak of the distribution is well above 10\%, with values of more than $20 \%$ being no rarity. By 1990 the distribution has shifted to the left with the peak now around 5\%. As globalization takes hold the distribution becomes strongly concentrated around a peak below $3 \%$. 


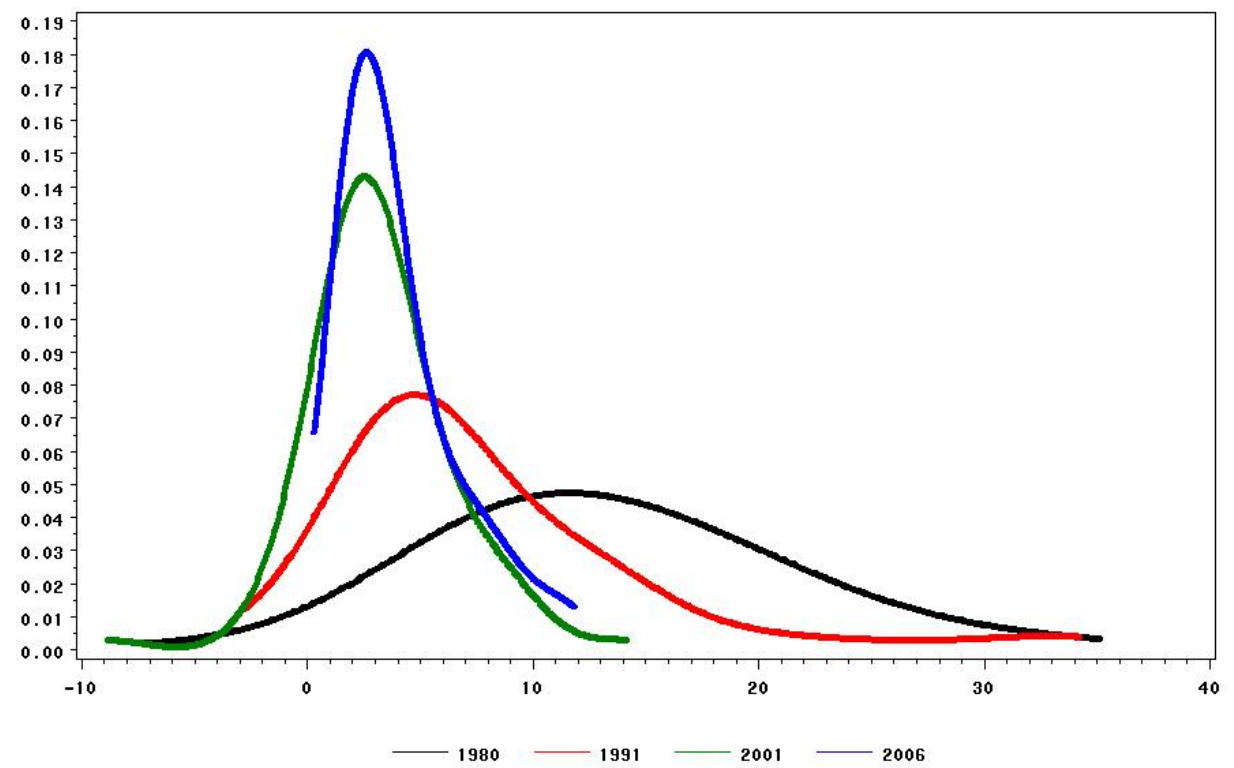

Figure 2: World cross country distribution of inflation.

Note: These curves are the Kernel density plots of inflation of countries with no missing
data between 1980 and 2006 in the International Monetary Fund Database, World Economic Outlook (WEO, IMF). Data in the vertical axis are frequencies in unit and those in the horizontal axis are inflation levels in percent.

Source: WEO, authors calculation.

Before proceeding to deeper analysis on causality, we will take a brief look at the correlation. Consider the following simple regression:

$$
\ln \text { Inflation }_{i t}=\alpha+\beta \ln \text { Openness }_{i t}+\epsilon_{i t} .
$$

This regression yields an estimated $\hat{\beta}=-0.62$ (standard error equal to 0.13 ), suggesting a strong and well-estimated negative relationship between openness and inflation: when openness rises by 10 percent, inflation decreases by 6.2 percent. The data of this regression are displayed as a scatterplot in Figure 3. Average inflation for a given country for the period 1980 to 2008 on the vertical axis is compared to average openness during the same period on the horizontal axis.

\section{The Model}

As we laid out in the empirical evidence, openness has an important effect on declining inflation. But what caused openness to rise in the first place? It seems striking that measures 
of openness show a sudden increase in the early 1990s. One effect might have been on the side of technology. It is for example much easier and cheaper to transmit software across large distances than manufactured goods, so that the technological revolution of the 1990s facilitated trade. But an even more important development took place on the political side. The balance of payments crisis brought many countries to look for assistance from the Bretton Wood Institutions. These advised and encouraged policies of the Washington Consensus, including more openness. This led countries around the world to leave protectionist policies and lower tariffs. India, as one example, reduced tariff rates from 133 in 1990 to 48 in 1997, as reported in Aghion et al. (2008).

This pattern can best be analysed in the framework of Melitz (2003). We modify it in a way that clearly highlights how lower transport cost increase openness and how greater openness affects inflation via foreign prices and productivity at home.

After making an investment in sunk entry cost new firms draw an initial productivity parameter $\varphi$ from a common distribution. In the model of Melitz, this distribution is not specified. Results are thus kept as general as possible, but it also strongly limits the ability of the model to make unambiguous predictions. In order to obtain clear statements on the variables of interest for this paper such as average productivity and prices, we replace the general distribution by the Pareto distribution as in Ottaviano and Melitz (2008), Ghironi and Melitz (2005) and Helpman et al. (2004). Luttmer (2007) provides empirical evidence that the Pareto distribution is a good approximation for firm sizes and thus implicitly for productivity levels.

Using the Pareto distribution, we can analyze the direction of change of the endogenous variables when parameters such as the level of fixed entry costs to the domestic and foreign market or transport cost change. On the side of parameters we concentrate on changes in transport cost. On the side of the variables, we consider some of those which are already defined in the Melitz paper such as average productivity and price levels. In addition we define a measure for openness.

In addition, we introduce money through a cash-in-advance constraint in order to explicitly analyse the effect of changes in relative prices on the price level. This will provide the link between the immediate real effects of trade and the monetary side.

In this section we will briefly present the model, using the Pareto distribution. 


\subsection{Setup of the Model}

\subsubsection{Demand}

Utility is given as a CES function. Since each variety is uniquely characterized by the productivity level $\varphi$ of the producing firm it can be written as

$$
U=\left[\frac{1}{1-G\left(\varphi^{*}\right)} \int_{\varphi^{*}}^{\infty} q(\varphi)^{\rho} N g(\varphi) d \varphi\right]^{\frac{1}{\rho}},
$$

where the elasticity of substitution is given by $\sigma=\frac{1}{1-\rho}>1$. After paying an initial entry cost, firms draw a productivity distributed by the Pareto distribution

$$
g(\varphi)=k \frac{\left(\varphi_{m}(t)\right)^{k}}{\varphi^{k+1}}
$$

where $\varphi_{m}(t)$ is the minimum of productivity draws. But only firms above an endogenous equilibrium cut-off value $\varphi^{*}$ are able to stay in the market. $\left(\varphi^{*}, \infty\right)$ is the interval of producing firms and $N$ indicates the mass of firms and goods. We assume $k>\sigma-1$ as in Ghironi and Melitz (2005) to assure that the variance of firm size is finite.

The minimum of productivity draws $\varphi_{m}(t)$ is defined as a function of time. This reflects that the distribution of productivity in an economy changes over time even in the absence of changes in trade volumes. Reflecting the historic trend of increasing productivity, there should be an upward trend in $\varphi_{m}(t)$. This implies a slow shift of the productivity distribution towards higher productivity. It would be possible at this point to introduce positive and negative productivity shocks, but since the focus of this paper is on long-term trends, we model technological development as a deterministic and exogenous process improving productivity at a constant rate $a$ :

$$
\varphi_{m}(t)=\varphi_{m 0} e^{a t}
$$

The set of varieties consumed can be written as an aggregate good $Q=U$ and the aggregate price is given by

$$
P=\left[\frac{1}{1-G\left(\varphi^{*}\right)} \int_{\varphi^{*}}^{\infty} p(\varphi)^{1-\sigma} N g(\varphi) d \varphi\right]^{\frac{1}{1-\sigma}} .
$$


Demand for each individual good will be given by

$$
q(\varphi)=Q\left[\frac{p(\varphi)}{P}\right]^{-\sigma}
$$

and revenue generated by one variety is

$$
r(\varphi)=R\left[\frac{p(\varphi)}{P}\right]^{1-\sigma}
$$

where $R=P Q$.

\subsubsection{Production}

Firms produce with a constant marginal cost, using only labor as an input. In order to set up the firm and enter the market, firms have to pay a sunk investment cost $f_{e}$. The effect of this will be discussed below for the free entry condition. In addition, firms pay a fixed overhead cost $f$ every period. Fixed overhead costs for exporting are $f_{x}>f$. Productivity is given by $\varphi$ and wages by $w$. Labor used can be written as $l=f+\frac{q}{\varphi}$. The investment cost plays no role once the firm is in the market because it is a sunk cost. Investment cost $f_{e}$ and overhead cost $f$ and $f_{x}$ are denoted in terms of labor. So the actual price that the firm has to pay is $w f_{e}, w f$ and $w f_{x}$.

Domestic firms therefore optimally set a price of

$$
p_{d}(\varphi)=\frac{w}{\rho \varphi} .
$$

For each exported good, firms have to pay a transport cost $\tau$, which increases their marginal cost. The price setting for export goods is thus

$$
p_{x}(\varphi)=\frac{\tau w}{\rho \varphi}
$$

Inserting (7) into (6), we can express revenues as

$$
r_{d}(\varphi)=R(P \rho \varphi)^{\sigma-1}
$$


Putting (8) into (6) yields the foreign revenues

$$
r_{x}(\varphi)=R(P \rho \varphi)^{\sigma-1} \tau^{1-\sigma}
$$

Profits in the home and export market can thus be written as

$$
\begin{aligned}
& \pi_{d}(\varphi)=r_{d}(\varphi)-l(\varphi)=\frac{r_{d}(\varphi)}{\sigma}-w f \\
& \pi_{x}(\varphi)=r_{x}(\varphi)-l(\varphi)=\frac{r_{x}(\varphi)}{\sigma}-w f_{x}
\end{aligned}
$$

\subsubsection{Revenue}

From (9) that domestic revenue can be written as

$$
r_{d}(\varphi)=\left(\frac{\varphi}{\varphi^{*}}\right)^{\sigma-1} r_{d}\left(\varphi^{*}\right)
$$

Recall that $\varphi^{*}$ is the marginal productivity at which a firm makes zero profits, $\pi_{d}\left(\varphi^{*}\right)=0$. Using (11), revenues are thus $r_{d}\left(\varphi^{*}\right)=\sigma w f$, so that we can write

$$
r_{d}(\varphi)=\left(\frac{\varphi}{\varphi^{*}}\right)^{\sigma-1} \sigma w f
$$

Using 100 we can write

$$
r_{x}(\varphi)=\tau^{1-\sigma} r_{d}(\varphi)=\tau^{1-\sigma}\left(\frac{\varphi}{\varphi^{*}}\right)^{\sigma-1} \sigma w f
$$

and

$$
\frac{r_{x}\left(\varphi_{x}^{*}\right)}{r_{d}\left(\varphi^{*}\right)}=\tau^{1-\sigma}\left(\frac{\varphi_{x}^{*}}{\varphi^{*}}\right)^{\sigma-1}
$$

where $\varphi_{x}^{*}$ is the cut-off level for exports at which firms make zero profits from exporting.

As above for domestic revenues we have $r_{x}\left(\varphi_{x}^{*}\right)=\sigma w f_{x}$ for export revenues, so that

$$
\frac{r_{x}\left(\varphi_{x}^{*}\right)}{r_{d}\left(\varphi^{*}\right)}=\frac{f_{x}}{f}
$$




\subsubsection{Productivity}

Joining (16) and (17) we obtain

$$
\varphi_{x}^{*}=\varphi^{*} \tau f^{*}
$$

where $f^{*}=\left[\frac{f_{x}}{f}\right]^{\frac{1}{\sigma-1}}$.

The weighted average of productivity is given by (see appendix for details)

$$
\begin{aligned}
\tilde{\varphi}\left(\varphi^{*}\right) & =\left[\frac{1}{1-G\left(\varphi^{*}\right)} \int_{\varphi^{*}}^{\infty} \varphi^{\sigma-1} g(\varphi) d \varphi\right]^{\frac{1}{\sigma-1}} \\
& =\left[\frac{\varphi^{* k}}{\varphi_{m}^{k}} \int_{\varphi^{*}}^{\infty} \varphi^{\sigma-1} k \frac{\varphi_{m}^{k}}{\varphi^{k+1}} d \varphi\right]^{\frac{1}{\sigma-1}} \\
& =k^{*} \varphi^{*}
\end{aligned}
$$

where $k^{*}=\left[\frac{k}{k-(\sigma-1)}\right]^{\frac{1}{\sigma-1}}$.

Average productivity abroad is given as

$$
\tilde{\varphi}\left(\varphi_{x}^{*}\right)=k^{*} f^{*} \tau \varphi^{*} .
$$

We define the share of exporters among domestic firms (which is also the probability of becoming an exporter for a new firm) as

$$
p_{x}=\frac{1-G\left(\varphi_{x}^{*}\right)}{1-G\left(\varphi^{*}\right)} .
$$

For the Pareto distribution this is (see appendix for details).

$$
p_{x}=\frac{1}{\left(\tau f^{*}\right)^{k}} .
$$

Average total productivity is defined by

$$
\tilde{\varphi}_{t o t}=\left(\frac{1}{N_{t o t}}\left[N \tilde{\varphi}^{\sigma-1}+N_{x}\left(\tau^{-1} \tilde{\varphi}_{x}\right)^{\sigma-1}\right]\right)^{\frac{1}{\sigma-1}},
$$

where $N_{t o t}=N+N_{x}$ and $N_{x}=p_{x} N$.

In the case of the Pareto distribution, this simplifies to (see appendix for details)

$$
\tilde{\varphi}_{t o t}=k^{*} \varphi^{*}\left(\frac{\tau^{k} f^{* k}+f^{* \sigma-1}}{\tau^{k} f^{* k}+1}\right)^{\frac{1}{\sigma-1}} .
$$




\subsection{Equilibrium}

It remains to determine average profits, noted $\bar{\pi}$ and the cutoff productivity level $\varphi^{*}$. Average profits are obtained as the sum of the differences between revenues and costs from export and domestic production. The resulting equation is termed zero cutoff profit (ZCP) condition by Melitz (2003). Using this, cutoff productivity is then obtained from the free entry (FE) condition which says that the net value of entry must be zero.

Average profits $\bar{\pi}$ are defined as

$$
\bar{\pi}=\pi_{d}(\tilde{\varphi})+p_{x} \pi_{x}\left(\tilde{\varphi}_{x}\right)
$$

Using (13) for $\tilde{\varphi}$ yields an equation for revenues

$$
r_{d}(\tilde{\varphi})=\left(\frac{\tilde{\varphi}}{\varphi^{*}}\right)^{\sigma-1} r_{d}\left(\varphi^{*}\right)
$$

which can be inserted into the profit function 11

$$
\pi_{d}(\tilde{\varphi})=\left(\frac{\tilde{\varphi}}{\varphi^{*}}\right)^{\sigma-1} \frac{r_{d}\left(\varphi^{*}\right)}{\sigma}-w f .
$$

Inserting $r_{d}\left(\varphi^{*}\right)=\sigma w f$ yields

$$
\bar{\pi}_{d}=\pi_{d}(\tilde{\varphi})=w f\left[\left(\frac{\tilde{\varphi}\left(\varphi^{*}\right)}{\varphi^{*}}\right)^{\sigma-1}-1\right]
$$

Export profits are derived analoguously as

$$
\bar{\pi}_{x}=\pi_{x}(\tilde{\varphi})=w f_{x}\left[\left(\frac{\tilde{\varphi}\left(\varphi_{x}^{*}\right)}{\varphi_{x}^{*}}\right)^{\sigma-1}-1\right]
$$

Inserting (28) and (29) into (26) we get

$$
\bar{\pi}=w f \cdot\left(\left[\frac{\tilde{\varphi}\left(\varphi^{*}\right)}{\varphi^{*}}\right]^{\sigma-1}-1\right)+p_{x} w f_{x} \cdot\left(\left[\frac{\tilde{\varphi}\left(\varphi_{x}^{*}\right)}{\varphi_{x}^{*}}\right]^{\sigma-1}-1\right)
$$

This is the Zero Cutoff Profit condition. For the case of the Pareto distribution it can be 
expressed as (see appendix for details)

$$
\bar{\pi}=\left(w f+\frac{1}{\tau^{k}} w f^{\frac{-k}{\sigma-1}} f_{x}^{1-\frac{-k}{\sigma-1}}\right) \frac{\sigma-1}{k-(\sigma-1)} .
$$

In order to keep notation clear we have so far abstained from using a time index. This was possible since all calculations made so far used only variables of the same period. To calculate the net value of entry however, we must sum over all expected future profits, so that we must introduce explicit time indices at this point. Average profits in period $t$ can be expressed as

$$
\bar{\pi}_{t}=\left(1+\pi_{0, t}^{w}\right) w_{0}\left(f+\frac{1}{\tau^{k}} f^{\frac{-k}{\sigma-1}} f_{x}^{1-\frac{-k}{\sigma-1}}\right) \frac{\sigma-1}{k-(\sigma-1)}
$$

where $\pi_{0, t}^{w}$ denotes wage inflation between 0 and $t$.

Every period each firm faces a probability $\delta$ of a bad shock that forces it to exit. The value of a firm is thus given as

$$
\bar{v}=\sum_{t=0}^{\infty}(1-\delta)^{t} \frac{1}{1+\pi_{0, t}^{w}} \bar{\pi}_{t}
$$

Firms weight each period by the probability of still being in the market at this point in the future and adjust for inflation. But since $\bar{\pi}_{t}$ can be written in a way that allows the inflation term to be factored out, the inflation terms cancel and the firm value can be written in real terms as

$$
\bar{v}=\frac{1}{\delta} \bar{\pi}_{0}
$$

The probability of drawing a productivity above the cutoff is denoted with $p_{i n}$. In order to enter the market firms pay a one-off sunk investment cost of $w f_{e}$. The net value of entry is

$$
v_{e}=p_{i n} \bar{v}-w_{0} f_{e}=\frac{1-G\left(\varphi^{*}\right)}{\delta} \bar{\pi}_{0}-w_{0} f_{e}
$$

In equilibrium there is free entry so that the net value of entry must be zero. The free 
entry condition is thus

$$
\begin{aligned}
\bar{\pi}_{0} & =\frac{\delta w_{0} f_{e}}{1-G\left(\varphi^{*}\right)} \\
& =\frac{\delta w f_{e} \varphi^{* k}}{\left(\varphi_{m}(t)\right)^{k}} .
\end{aligned}
$$

Combining FE and ZCP yields

$$
\varphi^{*}=\left[\frac{\left(\varphi_{m}(t)\right)^{k}}{\delta f_{e}}\left(f+\frac{1}{\tau^{k}} f^{\frac{-k}{\sigma-1}} f_{x}^{1-\frac{-k}{\sigma-1}}\right) \frac{\sigma-1}{k-(\sigma-1)}\right]^{\frac{1}{k}} .
$$

Substituting this value into the various expressions above allows to express the variables of the model depending on parameters. The equilibrium mass of domestic, exporting and total firms can be derived analogously to Melitz (2003) and is given by

$$
\begin{aligned}
N & =\frac{L}{\sigma\left(\bar{\pi}+f+p_{x} f_{x}\right)} \\
N_{x} & =\frac{p_{x} L}{\sigma\left(\bar{\pi}+f+p_{x} f_{x}\right)} \\
N_{\text {tot }} & =N+p_{x} N
\end{aligned}
$$

where $L$ aggregate labor.

\subsection{The Price Level}

Up to this point, the focus was on the real side of the economy. As can be expected, all productivity variables do not depend on wages and prices. But in order to link this model to inflation, a monetary side needs to be introduced. For this, we simply impose a cash-inadvance constraint which allows us to analyse inflation in straightfoward way.

The budget constraint is given on a period-by-period basis. Consumers earn wages $w$ and supply labor $L$ inelastically. Revenue $R$ is spent on consumption goods and can be written as the product of average prices $p(\tilde{\varphi})$, the average quantity supplied by each firm $q(\tilde{\varphi})$ and the mass $N$ of active firms:

$$
w L=p(\tilde{\varphi}) q(\tilde{\varphi}) N
$$

We impose a cash-in-advance constraint meaning that consumers have to hold money $M$ 
equal to the total amount of purchases. And since purchases equal revenue, we can write

$$
\begin{aligned}
M & =R \\
& =p(\tilde{\varphi}) q(\tilde{\varphi}) N \\
& =w \frac{1}{\rho \tilde{\varphi}} q(\tilde{\varphi}) N .
\end{aligned}
$$

\subsection{Results}

Lower transport cost eliminates the least productive domestic firms and increases the weight of high-productivity foreign firms in the domestic productivity index. A decrease in transport cost leads to a new level of $\operatorname{cost} \tau^{\prime}$ with $\tau>\tau^{\prime}>1$.

Proposition 1 Average productivity in a country increases as the transport cost decreases.

$$
\frac{\partial \tilde{\varphi} \tilde{t o t}}{\partial \tau}<0
$$

For a given level of wages w average prices in the home country fall when transport costs fall:

$$
\frac{\partial \tilde{p}}{\partial \tau}>0
$$

\section{Proof}

In equation 25), average total productivity is given by

$$
\tilde{\varphi}_{t o t}=k^{*} \varphi^{*}\left(\frac{\tau^{k} f^{* k}+f^{* \sigma-1}}{\tau^{k} f^{* k}+1}\right)^{\frac{1}{\sigma-1}}
$$

Denoting $F=\frac{\tau^{k} f^{* k}+f^{* \sigma-1}}{\tau^{k} f^{* k}+1}$, the derivation can be written as

$$
\frac{\partial \tilde{\varphi}_{t o t}}{\partial \tau}=k^{*}\left[\frac{\partial \varphi^{*}}{\partial \tau} F^{\frac{1}{\sigma-1}}+\varphi^{*} \frac{1}{\sigma-1} F^{\frac{2-\sigma}{\sigma-1}} \frac{\partial F}{\partial \tau}\right] .
$$

We now have to determine the sign of each of these terms: 


$$
\begin{aligned}
\frac{\partial F}{\partial \tau} & =\frac{k \tau^{k-1} f^{* k}\left(\tau^{k} f^{* k}+1\right)-\left(\tau^{k} f^{* k}+f^{* \sigma-1}\right) k \tau^{k-1} f^{* k}}{\left(\tau^{k} f^{* k}+1\right)^{2}} \\
& =\frac{k \tau^{k-1} f^{* k}-f^{* \sigma-1} k \tau^{k-1} f^{* k}}{\left(\tau^{k} f^{* k}+1\right)^{2}} \\
& =\frac{k \tau^{k-1} f^{* k}\left(1-f^{* \sigma-1}\right)}{\left(\tau^{k} f^{* k}+1\right)^{2}} \\
& =\frac{k \tau^{k-1} f^{* k}\left(1-\frac{f_{x}}{f}\right)}{\left(\tau^{k} f^{* k}+1\right)^{2}}<0
\end{aligned}
$$

since $f<f_{x} \Leftrightarrow 1<\frac{f_{x}}{f}$.

Taking derivatives from 35 , we have $\frac{\partial \varphi^{*}}{\partial \tau}<0$. This means that cutoff productivity increases, when transport cost fall.

Substituting $\frac{\partial F}{\partial \tau}<0$ and $\frac{\partial \varphi^{*}}{\partial \tau}<0$ into 42 we have

$$
\frac{\partial \tilde{\varphi}_{t}}{\partial \tau}<0
$$

This completes the proof for the first statement. The second statement follows almost immediately. By the definition of $\tilde{\varphi}_{t o t}$, the average price of firms is given by the price of the firm with average productivity

$$
\tilde{p}=p\left(\tilde{\varphi}_{t o t}\right)
$$

Using the equation for prices (7) and proposition 1 we have

$$
\frac{\partial p\left(\tilde{\varphi}_{t o t}\right)}{\partial \tau}=-\frac{w}{\rho \tilde{\varphi}_{t o t}^{2}} \frac{\partial \tilde{\varphi}_{t o t}}{\partial \tau}>0
$$

As the next step we show the theoretical link between transport cost and our measure of openness. Openness is defined as imports plus exports over GDP. But since countries are identical in this paper, imports are actually equal to exports. We define $R_{x}$ as the total revenues from export and $R_{d}$ as total revenues from domestic sales. Openness is then given 
as

$$
\text { Openness }=\frac{\text { Imports }+ \text { Exports }}{G D P}=\frac{2 \cdot \text { Exports }}{G D P}=\frac{2 \cdot R_{x}}{R_{d}+R_{x}}
$$

where

$$
\begin{aligned}
& R_{d}=\int_{\varphi^{*}}^{\infty} r_{d}(\varphi) N g(\varphi) d \varphi \\
& R_{x}=\int_{\varphi_{x}^{*}}^{\infty} r_{x}(\varphi) N_{x} g(\varphi) d \varphi .
\end{aligned}
$$

The integration limits are illustrated by the following list of production and export status:

\section{Interval Production Status}

$\left[\varphi_{m}, \varphi^{*}\right] \quad$ no production

$\left[\varphi^{*}, \varphi_{x}^{*}\right] \quad$ production for domestic market

$\left[\varphi_{x}^{*}, \infty\right] \quad$ production for domestic market and export $r_{d}(\varphi)+r_{x}(\varphi)$

\section{Total Revenue}

0

$r_{d}(\varphi)$

Proposition 2 Openness increases as the transport cost decreases.

$$
\frac{\partial \text { Openness }}{\partial \tau}<0
$$

Proof Taking derivatives of domestic revenue (14) with respect to transport cost, we have

$$
\frac{\partial r_{d}(\varphi)}{\partial \tau}=\varphi^{\sigma-1} \sigma w f(1-\sigma) \frac{\partial \varphi^{*}}{\partial \tau}>0
$$

since $\frac{\partial \varphi^{*}}{\partial \tau}<0$ and $\sigma>1$.

The mass $N$ of firms as given in equation (36). An decrease in transport cost $\tau$ increases the probability of exporting $p_{x}$ as given in $(23)$, which in turn reduces the equilibrium number of domestic firms $N$.

In addition, the lower bound of integration for $R_{d}$, given by $\varphi^{*}$, increases because of decreasing transport cost. In all, we can conclude

$$
\frac{\partial R_{d}}{\partial \tau}>0
$$

meaning that total revenue from domestic sales falls as a consequence of lower transport cost. 
Taking derivatives of export revenue (15) with respect to transport cost, we have

$$
\frac{\partial r_{x}(\varphi)}{\partial \tau}=\varphi^{\sigma-1} \sigma w f(1-\sigma)\left(\tau \varphi^{*}\right)^{-\sigma}\left(\frac{\partial\left(\tau \varphi^{*}\right)}{\partial \tau}\right)<0
$$

To see this, note that using (35) we get

$$
\tau \varphi^{*}=\left[\frac{\varphi_{m}^{k}}{\delta f_{e}}\left(\tau^{k} f+f^{\frac{-k}{\sigma-1}} f_{x}^{1-\frac{-k}{\sigma-1}}\right) \frac{\sigma-1}{k-(\sigma-1)}\right]^{\frac{1}{k}}
$$

which depends positively on $\tau$.

The effect of transport cost on the mass of exporters is given by the derivative of (37):

$$
\frac{\partial N_{x}(\varphi)}{\partial \tau}=\frac{L \sigma \bar{\pi}+f}{\left(\sigma\left(\bar{\pi}+f+p_{z}+f_{x}\right)\right)^{2}}\left(-\frac{k}{f^{* k} \tau^{k+1}}\right)<0 .
$$

Taking derivatives of the export cut-off level (18) with respect to transport cost, we have

$$
\frac{\partial \varphi_{x}^{*}}{\partial \tau}=f^{*}\left(\frac{\partial\left(\tau \varphi^{*}\right)}{\partial \tau}\right)>0
$$

meaning that the lower bound of integration for $R_{x}$ falls when transport costs fall. In all, we have

$$
\frac{\partial R_{x}}{\partial \tau}<0
$$

Using the expression for openness from (43), this yields the result.

Combining propositions 1 and 2 shows the close connection between openness and productivity.

Proposition 3 If propositions 1 and 2 hold, then ceteris paribus, every increase in openness implies an increase in productivity.

Proof As Proposition 2 illustrates openness is strictly monotonely increasing in transport cost. Every level of openness is thus connected to a unique level of transport cost, the two variables are linked by a one-to-one relationship. Given proposition 1, every increase in openness means that productivity must rise as well. 
The results so far treated the effect of changes in tranport cost on the economy. Next, we turn to the innovative process which increases productivity in a country over time even in the absence of globalization. The first observation is that the average productivity of firms in the market increases as the distribution of productivity draws moves to the right. This statement is non-trivial since the fraction of firms that is able to stay in the market is endogenously determined.

Proposition 4 The average productivity of firms in the market increases over time

$$
\frac{\partial \tilde{\varphi_{t o t}}}{\partial t}>0
$$

Proof From equation 25) we can see that average productivity of firms in the market increases linearly in the cut-off level of productivity $\varphi^{*}$. The cut-off level itself depends linearly on the minimum level of productivity draws $\varphi_{m}(t)$, see equation (35). The minimum level of productivity was assumed to grow at a constant rate over time, equation (3).

In analogy to the case of transport cost, we can determine the effect of time via productivity on prices. Given assumption (3) quality-adjusted relative prices of goods become cheaper in terms of the wage over time.

Using equation (40) we can now summarize our results on the central role of productivity for inflation. The growth rate of a variable $x$ is noted as $g_{x}$.

Proposition 5 Inflation can be written as the difference in the growth rate of the money supply and total productivity

$$
\pi=g_{M}-g_{\varphi_{\tilde{t o t}}}
$$

whereas productivity depends on time as a result of innovation and on openness as a result of firm selection.

Proof From the budget constraint, we have $\frac{1}{\rho \varphi_{t o t}} q(\tilde{\varphi}) N=L$ which is constant. Using 40, this allows to write

$$
g_{M}=g_{w} .
$$


Inflation can now be written in this way:

$$
\begin{aligned}
\pi & =g_{p} \\
& =g_{w}-g_{\varphi \tilde{t o t}} \\
& =g_{M}-g_{\varphi \tilde{t} o t}
\end{aligned}
$$

Given propositions 1 and 4, all increases in productivity resulting from innovation or firm selection as a consequence of lower transport cost (resp. higher openness) which are not actively offset by increases in the money supply, decrease inflation.

If monetary policy is constant $M_{t}=M_{0} \cdot e^{t g_{M}}$, then all changes in inflation are driven by changes in average productivity. Furthermore, equation (46) shows why the model can explain the reduction in world wide inflation generally without having to explain the disappearance of hyperinflation such as the one in Latin America in the early 90s: The disappearance of hyperinflations is caused by better monetary policy reflected in the growth of money supply $g_{M}$.

However it may be that monetary policy is not independant of productivity. If the central bank wants to keep inflation constant for example it could make the money supply dependend on productivity $M(\tilde{\varphi})$ with $M^{\prime}(\tilde{\varphi})<0$ such that $g_{M}=g_{\tilde{\varphi}}$. In this case, changes in productivity would be neutralised by monetary policy. For the historic development, this seems implausible since low levels of inflation are generally seen as desirable. It may however be the case of countries which already have low levels of inflation as central banks want to avoid deflation.

\section{Estimation and Methodology}

In section 2 we saw that inflation has fallen strongly as globalization deepened. This might of course be a coincidence only. Many explanations for falling inflation have been put forward, most prominently improved monetary policy. In this section we will seek to establish a causal link, controlling for monetary variables. 


\subsection{Description of the data}

The data used for our regression analysis originates from various sources. Since productivity data are not available for all countries, we approximate it by GDP per capita, whereas the data for real GDP per capita is taken from the Penn World Table (6.2). In studies involving a large number of countries, this approximation of productivity is a frequently used procedure (see for example Rodrik (2009) and Rogoff (1996)). To illustrate why this is a good approximation, see figure 4. The figure plots the growth rate of GDP against that of productivity for all countries where data on productivity is available. Openness is defined as in the theoretical model: the ratio of the sum of exports plus imports relative to GDP, the data also comes from the Penn World Table (6.2).

Our exchange rate regime classification is based on Levy-Yeyati and Sturzenegger (2003). They use a de facto classification of exchange rate regimes based on cluster analysis techniques. Countries are sorted according to three variables: (i) Exchange rate volatility, (ii) Volatility of exchange rate changes, and (iii) Volatility of reserves. They are classified into three categories: $1=$ float; $2=$ intermediate and $3=$ fixed.

The remaining economic variables are all taken from the World Development Indicators (WDI) of the World Bank from September 2010. The consumer price index, the dependent variable, is in the form of annual log differences. Government burden is defined as the ratio of total government consumption relative to GDP. Money and quasi money is the total money supply or M2 over GDP. "It comprises the sum of currency outside banks, demand deposits other than those of the central government, and the time, savings, and foreign currency deposits of resident sectors other than the central government", according to the World Bank.

The Freedom House and Political Rights Index is used as a proxy for quality of institutions. A country receives the highest score if political rights are close to some ideals (free and fair elections, competitive parties, minorities have reasonable self government, etc. $)_{1}^{1}$. We transform this index via a logistic transformation to the interval between zero and one, where one is the best possible score for quality of institutions. Since inflation tends to increase during war periods, we control also for war episodes. The data for war episodes is taken from Fearon and Laitin (2003).

We compiled a dataset of the above named variables for 175 countries. All countries

\footnotetext{
${ }^{1}$ Freedom House, 2009. Freedom in the World http://www.freedomhouse.org/uploads/fiw09/CompHistData/FIW_AllScores_Coutries.xls
} 
that have not at least 20 consecutive observations for inflation are deleted. We also delete seven countries which experienced hyperinflation periods because we believe that in theses countries, inflation is mainly driven by money supply: Argentina, Bolivia, Brazil, Croatia, Peru, Poland, Democratic Republic of Congo and Zimbabwe. This leaves a final sample of 107 countries with annual data for the period 1970-2009. The panel is unbalanced. See table 10 for the list of countries included in the sample and table 9 for the summary statistics.

\subsection{Predictions derived from the theoretical model}

Proposition 5 contains the main result of the paper: Inflation can be written as the difference of the growth rate of the money supply and the growth rate of productivity

$$
\pi=g_{M}-g_{\tilde{\varphi}_{t o t}}
$$

The growth rate of productivity in turn depends on time (Proposition 4) as it evolves as a result of ongoing innovative activity and on increases in openness (Proposition 3) which causes firm selection. In order to test our theoretical result, the most straighforward thing to do is therefore to estimate this equation. We implement it empirically as:

$$
\begin{aligned}
\Delta \ln \mathrm{CPI}_{i, t} & =\beta_{0}+\beta_{1} \Delta \ln \frac{M 2}{G D P}+\beta_{2} \Delta \ln \text { Productivity }_{i, t}+\beta_{3} \Delta \ln \text { Productivity }_{i, t} * \Delta \ln \text { Openness }_{i, t} \\
& +\beta_{4} \Delta \ln \operatorname{Openness}_{i, t}+\beta_{5} \Delta \ln \mathrm{CPI}_{i, t-1}+\beta^{\prime} X_{i, t}+\mu_{t}+\gamma_{i}+\epsilon_{i, t}
\end{aligned}
$$

where $i=1, \cdots, 107, t=1, \cdots, 40$ and $\Delta$ is the first difference. All variables are set in log differences except the dummies. The dependent variable is the growth rate of the consumer price index. The first explanatory variable is the ratio of M2 to GDP followed by the two sources of productivity growth. Productivity is the log difference of GDP per capita and openness is the log difference of the ratio of import plus export over gross domestic product. Control variables are openness and the lagged value of inflation to capture persistence in inflation and potentially mean-reverting dynamics. Further controls are captured in $X_{i, t}$ including the exchange rate regime dummy (Levy-Yeyati and Sturzenegger (2003)) and the ratio of government consumption to GDP (government burden). $\gamma_{i}$ is the country-fixed effect and $\epsilon_{i, t}$ the error term.

This regression equation explicitely models the two types of productivity changes: changes that occur independently from trade are captured by $\beta_{2}$ and those occuring as a consequence 
of greater openness through the mechanism of the model are captured by $\beta_{3}$. The derivative of inflation with respect to productivity can thus be expressed as

$$
\frac{\partial \Delta \ln \text { Inflation }}{\partial \Delta \ln \text { Productivity }}=\beta_{2}+\beta_{3} \cdot \Delta \ln \text { Openness }
$$

with $\beta_{2}<0$ and $\beta_{3}<0$. A negative $\beta_{3}$ implies that the marginal effect of productivity on inflation is more strongly negative in more open economies.

\subsubsection{Endogeneity and Other Concerns}

We estimate the above equation using simple OLS with country fixed effects and OLS with country fixed effect, robust standard errors and clustered countries. By introducing country fixed effects, the idea is to move beyond cross country comparison by investigating withincountry variation: Is France more likely to have lower inflation when it becomes relatively more open? By clustering countries, we allow for intragroup correlation, relaxing the previous hypothesis that the observations are independent across groups but not necessarily within groups.

When using OLS there is a pitfall even if with country fixed effect, robust standard errors and clustered countries: The endogeneity of productivity. One possible source of this is reverse causality: more inflation leads to lower productivity because inflation volatility reduces along with volatility thus reducing risk and increasing competition. The second cause of endogeneity is simultaneous causality: an omitted variable (like the quality of institutions) causes productivity to increase and inflation to decrease. To deal with this problem, we use the system of Generalized Method of Moments (GMM). Note that when system GMM is used, it is not good to include explicit fixed effect dummies since it might cause bias, cf. Roodman 2006). We do not cluster countries because GMM's standard errors are robust.

\subsubsection{Estimation Results}

The main estimation results are shown in tables 3 to 5 . Table 3 shows the effect of the growth rates of a range of explanatory variables on inflation using OLS. Column (1) includes only a minimum of explanatory variables and the following columns successively add more. We find all variables to be significant at the $1 \%$-level with the exception of the exchange rate regime.

Starting with the control variables, we find that inflation inertia has a positive sign, confirming the notion of the persistence of changes in inflation. The government burden 
- somewhat surprisingly - has a negative sign, suggesting that an increase in government spending reduces inflation. The control was included since Aghion et al. (2009) document a strong correlation between government consumption and productivity. The exchange rate regime is found to be insignificant. This control was included to take into account that a large number of countries use, officially or de facto, the euro or the dollar or have a fixed exchange rate to one of these currencies. The insignificance of this control variable suggests that the use of a common currency does not lead to common inflation levels. In line with monetary theory we find that growth in the money supply has a positive effect on inflation.

Now coming to that variables of interest to our theory we find that an increase in openness reduces inflation. This confirms previously proposed theories for a link between openness and inflation such as the idea of a reduced incentive for surprise disinflations put forward by Rogoff (2003). An increase in productivity also lowers inflation, thus supporting the idea that a reduction in relative prices for goods does to some extent affect the price level. Finally, and crucially for our theory, the interaction term between openness and productivity also has a negative effect on inflation. This confirms the central concept of this paper that opennessinduced productivity changes reduce the price level via lower relative prices for goods.

Table 4 is designed the same way, but employs OLS with country clusters. This more robust method controls for correlation within and across countries. Table 5 goes one step further and applies GMM, so that we can be sure that results are robust to autocorrelation, heteroskedasticity and endogeneity. Country-fixed effects are left out here, since they are not needed with GMM. The results of these two tables vary only slightly from those with OLS, so that we can consider the results confirmed.

Alfaro (2005) documents the role of the exchange rate regime on inflation. Without controlling for productivity, she concludes that the exchange rate regime is more relevant than openness as an explanation of inflation. Our results however show that productivity provides the link between openness and inflation. Openness via productivity has a stronger impact on the level of inflation than the exchange rate regime. We find the effect of the exchange rate regime on inflation to be insignificant.

\subsection{Robustness Check: The Role of Institutions and Other Factors}

It is possible that the correlation between changes in productivity and inflation is due to an omitted variable. An improvement in institutions or political leadership might cause both 
inflation to go down and trade to increase. The idea behind this is that leaders simultaneously stop using inflation taxation and start opening their countries in an attempt to improve economic performance. A sudden change of economic policy like this might be introduced by newly elected leaders or as an attempt to implement the Washington Consensus. If this hypothesis is right and if the quality of institutions could be observed, we could run the regression:

$$
\begin{aligned}
\Delta \ln \mathrm{CPI}_{i, t} & =\beta_{0}+\beta_{1} \Delta \ln \frac{M 2}{G D P}+\beta_{2} \Delta \ln \text { Productivity }_{i, t}+\beta_{3} \Delta \ln \operatorname{Productivity}_{i, t} * \Delta \ln \text { Openness }_{i, t} \\
& +\beta_{4} \Delta \ln \text { Openness }_{i, t}+\beta_{5} \Delta \ln _{\mathrm{CPI}_{i, t-1}}+\beta_{6} \text { Institutions }_{i, t}+\beta_{7} \operatorname{War}_{i, t} \\
& +\beta^{\prime} X_{i, t}+\mu_{t}+\gamma_{i}+\epsilon_{i, t}
\end{aligned}
$$

It is difficult to measure the quality of institutions directly of course. But we may get a good idea of major changes in institutional quality from an index such as the "Freedom in the World"-index from Freedom House. This index measures the quality of political rights in a country and can be seen as an indicator of any sincere attempt to improve governance. So if the correlation between openness and inflation is indeed driven by institutional quality, the inclusion of any measure for institutional quality should dramatically reduce the significance of productivity and openness in the regressions. Including the index (see tables 6, 7 and 8) we find that this is not the case. We find that the "Freedom in the World"-index itself is not significant and does not strongly change the effect of openness, productivity and its interaction.

A similar concern is the effect of wars. Wars might force a country to reduce international trade and drive up inflation. Controlling for this with the inclusion of a war dummy, we find that the dummy is indeed a weakly significant driver of inflation, but that this doesn't reduce the importance of the other variables.

\section{Conclusion}

This paper explores the central role of productivity as a link between openness to trade and inflation in a framework of heterogenous firms. Theoretically, we adapt the model of Melitz (2003) to make explicitely statements on the reaction of openness, productivity and relative prices to changes in transport cost. In addition a CIA constraint permits to understand how the relative price changes translate into the price level and affect inflation. 
Empirically, we make use of a purpose-made dataset containing all the relevant variables for 107 countries from all regions of the world. Estimation of the central theoretical equation reveals a significant effect of openness-induced productivity increase on inflation. Using an instrumental variable approach and directly controlling for institutional quality we give strong evidence that results are robust to omitted variable bias and reverse causality.

As a consequence of our result the question arises how sustainable the low levels of inflation are. An increase in openness leads to an acceleration in productivity, but only temporarily. Once openness stabilizes, theory predicts that inflation should rise to a higher level, because productivity growth is no longer aided by firm selection from additional foreign competition. But since openness increased continuously up to the present, it remains to be seen whether central banks can keep inflation low or if it edges back up a bit as soon as openness has reached a peak. 


\section{References}

Aghion, P., Bacchetta, P., Ranciere, R., and Rogoff, K. (2009). Exchange rate volatility and productivity growth: the role of financial development. Journal of Monetary Economics, 56(4):494-513.

Aghion, P., Burgess, R., Redding, S., and Zilibotti, F. (2008). The unequal effects of liberalization: Evidence from dismantling the License Raj in India. American Economic Review, 98(4):1397-1412.

Alfaro, L. (2005). Inflation, openness, and exchange-rate regimes:: The quest for short-term commitment. Journal of Development Economics, 77(1):229-249.

Auer, R. and Fischer, A. (2010). The effect of low-wage import competition on US inflationary pressure. Journal of Monetary Economics, 57(4):491-503.

Bernard, A., Eaton, J., Jensen, J., and Kortum, S. (2003). Plants and productivity in international trade. American Economic Review, 93(4):1268-1290.

Bernard, A., Jensen, J., and Schott, P. (2006). Trade costs, firms and productivity. Journal of Monetary Economics, 53(5):917-937.

Chen, N., Imbs, J., and Scott, A. (2004). Competition, Globalization, and the Decline of Inflation. SSRN eLibrary.

Chen, N., Imbs, J., and Scott, A. (2009). The dynamics of trade and competition. Journal of International Economics, 77(1):50-62.

Fearon, J. and Laitin, D. (2003). Ethnicity, insurgency, and civil war. American Political Science Review, 97(01):75-90.

Ghironi, F. and Melitz, M. (2005). International Trade and Macroeconomic Dynamics with Heterogeneous Firms*. The Quarterly Journal of Economics, 120(3):865-915.

Guerrieri, L., Gust, C. J., and Lopez-Salido, D. (2009). International Competition and Inflation: A New Keynesian Perspective. SSRN eLibrary.

Helpman, E., Melitz, M., and Yeaple, S. (2004). Export versus FDI with heterogeneous firms. The American Economic Review, 94(1):300-316. 
Levy-Yeyati, E. and Sturzenegger, F. (2003). To float or to fix: evidence on the impact of exchange rate regimes on growth. American Economic Review, 93(4):1173-1193.

Luttmer, E. (2007). Selection, Growth, and the Size Distribution of Firms. The Quarterly Journal of Economics, 122(3):1103-1144.

Melitz, M. (2003). The impact of trade on intra-industry reallocations and aggregate industry productivity. Econometrica, 71(6):1695-1725.

Ottaviano, G. and Melitz, M. (2008). Market Size, Trade, and Productivity. Review of Economic Studies, 75:295-316.

Pavcnik, N. (2002). Trade liberalization, exit, and productivity improvements: Evidence from Chilean plants. The Review of Economic Studies, 69(1):245-276.

Rodrik, D. (2009). The real exchange rate and economic growth. Brookings Papers on Economic Activity, 2008(2):365-412.

Rogoff, K. (1996). The purchasing power parity puzzle. Journal of Economic Literature, 34(2):647-668.

Rogoff, K. (2003). Globalization and global disinflation. Economic Review-Federal Reserve Bank of Kansas City, 88(4):45-80.

Romer, D. (1993). Openness and inflation: theory and evidence. The Quarterly Journal of Economics, 108(4):869-903.

Roodman, D. (2006). How to do xtabond2: An introduction to difference and system GMM in Stata. Center for Global Development.

Syverson, C. (2004). Market structure and productivity: A concrete example. Journal of Political Economy, 112(6):1181-1222. 


\section{A Appendix}

\section{A.1 Simple Derivations}

\section{Average Productivity at Home}

$$
\begin{aligned}
\tilde{\varphi}\left(\varphi^{*}\right) & =\left[\frac{\varphi^{* k}}{\left(\varphi_{m}(t)\right)^{k}} \int_{\varphi^{*}}^{\infty} \varphi^{\sigma-1} k \frac{\left(\varphi_{m}(t)\right)^{k}}{\varphi^{k+1}} d \varphi\right]^{\frac{1}{\sigma-1}} \\
& =\left[\varphi^{* k} k \int_{\varphi^{*}}^{\infty} \frac{\varphi^{\sigma-1}}{\varphi^{k+1}} d \varphi\right]^{\frac{1}{\sigma-1}} \\
& =\left[\varphi^{* k} k \int_{\varphi^{*}}^{\infty} \varphi^{\sigma-k-2} d \varphi\right]^{\frac{1}{\sigma-1}} \\
& =\left[\varphi^{* k} k\left|\frac{1}{\sigma-k-1} \varphi^{\sigma-k-1}\right|_{\varphi^{*}}^{\infty}\right]^{\frac{1}{\sigma-1}} \\
& =\left[\varphi^{* k} \frac{k}{k-(\sigma-1)} \varphi^{* \sigma-1-k}\right]^{\frac{1}{\sigma-1}} \\
& =\left[\frac{k}{k-(\sigma-1)} \varphi^{* \sigma-1}\right]^{\frac{1}{\sigma-1}} \\
& =\left[\frac{k}{k-(\sigma-1)}\right]^{\frac{1}{\sigma-1}} \varphi^{*}
\end{aligned}
$$

Note that $\left[\frac{k}{k-(\sigma-1)}\right]^{\frac{1}{\sigma-1}}>0$.

Average productivity Abroad

$$
\begin{aligned}
\tilde{\varphi}\left(\varphi_{x}^{*}\right) & =\tilde{\varphi}\left(\tau\left(\frac{f_{x}}{f}\right)^{\frac{1}{\sigma-1}} \varphi^{*}\right) \\
& =\left[\frac{k}{k-(\sigma-1)} \tau^{\sigma-1} \frac{f_{x}}{f} \varphi^{* \sigma-1}\right]^{\frac{1}{\sigma-1}} \\
& =\left[\frac{k}{k-(\sigma-1)} \frac{f_{x}}{f}\right]^{\frac{1}{\sigma-1}} \tau \varphi^{*}
\end{aligned}
$$

Probability of Exporting

$$
p_{x}=\frac{1-G\left(\varphi_{x}^{*}\right)}{1-G\left(\varphi^{*}\right)}=\frac{\left(\frac{\left(\varphi_{m}(t)\right)}{\varphi_{x}^{*}}\right)^{k}}{\left(\frac{\left(\varphi_{m}(t)\right)}{\varphi^{*}}\right)^{k}}=\frac{\varphi^{* k}}{\varphi_{x}^{* k}}=\frac{1}{\left(\tau f^{*}\right)^{k}}
$$


Average total productivity Inserting the definitions of $N_{t o t}$ and $N_{x}$ into the definition of average total productivity (24) we can write

$$
\tilde{\varphi}_{t o t}=\left(\frac{1}{1+p_{x}}\left[\tilde{\varphi}^{\sigma-1}+p_{x}\left(\tau^{-1} \tilde{\varphi}_{x}\right)^{\sigma-1}\right]\right)^{\frac{1}{\sigma-1}} .
$$

Substituting in the expressions from (20), 21) and (23) we obtain

$$
\begin{aligned}
\tilde{\varphi}_{t o t} & =\left(\frac{1}{1+\left(\tau f^{*}\right)^{-k}}\left[\left(k^{*} \varphi^{*}\right)^{\sigma-1}+\left(\tau f^{*}\right)^{-k}\left(k^{*} f^{*} \varphi^{*}\right)^{\sigma-1}\right]\right)^{\frac{1}{\sigma-1}} \\
& =k^{*} \varphi^{*}\left(\frac{\tau^{k} f^{* k}+f^{* \sigma-1}}{\tau^{k} f^{* k}+1}\right)^{\frac{1}{\sigma-1}} .
\end{aligned}
$$

The zero cutoff profit function (ZCP)

$$
\begin{aligned}
\bar{\pi} & =f \cdot\left(\left[\frac{\tilde{\varphi}\left(\varphi^{*}\right)}{\varphi^{*}}\right]^{\sigma-1}-1\right)+p_{x} f_{x} \cdot\left(\left[\frac{\tilde{\varphi}\left(\varphi_{x}^{*}\right)}{\varphi_{x}^{*}}\right]^{\sigma-1}-1\right) \\
& =f\left[\frac{k^{*} \varphi^{*}}{\varphi^{*}}\right]^{\sigma-1}-f+\frac{1}{\left(\tau f^{*}\right)^{k}} f_{x}\left[\frac{k^{*} f^{*} \tau \varphi^{*}}{f^{*} \tau \varphi^{*}}\right]^{\sigma-1}-\frac{1}{\left(\tau f^{*}\right)^{k}} f_{x} \\
& =f\left[\frac{k}{k-(\sigma-1)}\right]-f+\frac{1}{\left(\tau f^{*}\right)^{k}} f_{x}\left[\frac{k}{k-(\sigma-1)}\right]-\frac{1}{\left(\tau f^{*}\right)^{k}} f_{x} \\
& =\left(f+\frac{1}{\left(\tau f^{*}\right)^{k}} f_{x}\right)\left[\frac{k}{k-(\sigma-1)}\right]-\left(f+\frac{1}{\left(\tau f^{*}\right)^{k}} f_{x}\right) \\
& =\left(f+\frac{1}{\left(\tau f^{*}\right)^{k}} f_{x}\right)\left[\frac{k}{k-(\sigma-1)}-1\right] \\
& =\left(f+\frac{1}{\tau^{k}}\left(\frac{f_{x}}{f}\right)^{\frac{k}{\sigma-1}} f_{x}\right)\left[\frac{\sigma-1}{k-(\sigma-1)}\right] \\
& =\left(f+\frac{1}{\tau^{k}} f^{\frac{-k}{\sigma-1}} f_{x}^{1-\frac{-k}{\sigma-1}}\right) \frac{\sigma-1}{k-(\sigma-1)}
\end{aligned}
$$




\section{A.2 Graphical Appendix}

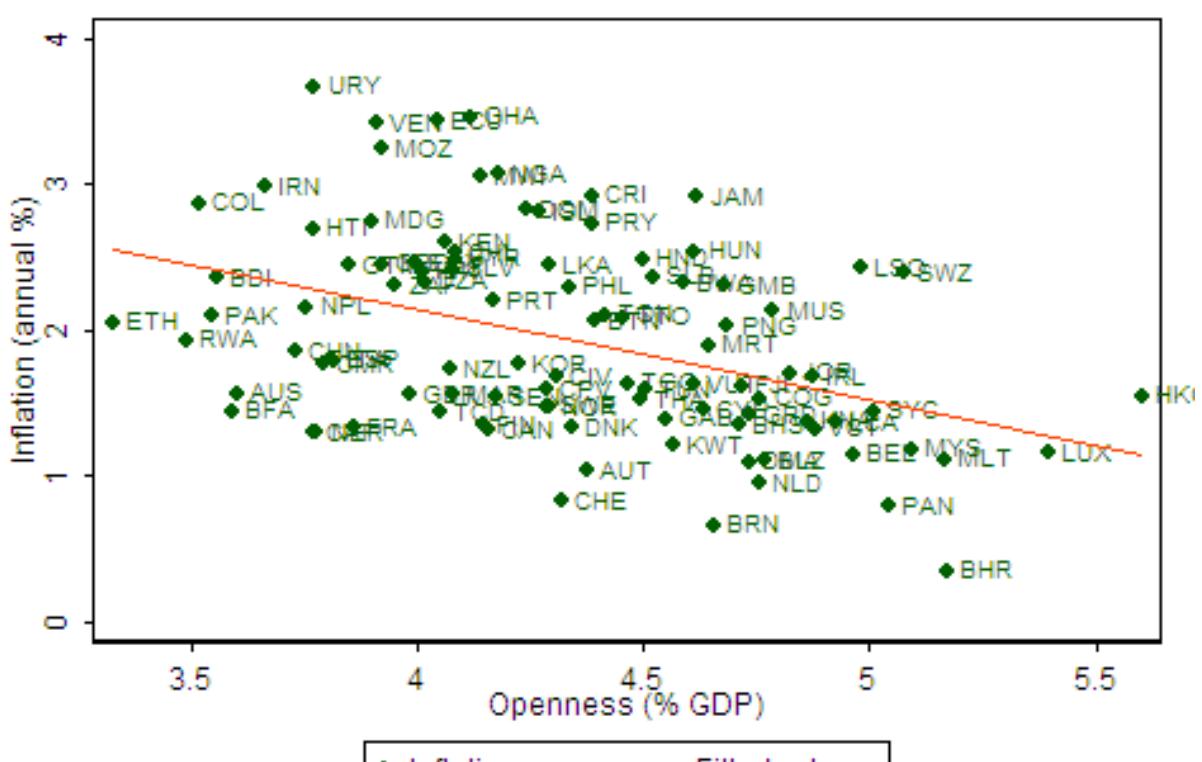

- Inflation Fitted values

Source: Authors's calculation based on data from WDI, $y=-0.62(0.13) x+4.8(0.59)$

Figure 3: Inflation and Openness for 1980 to 2008, logarithmic scale

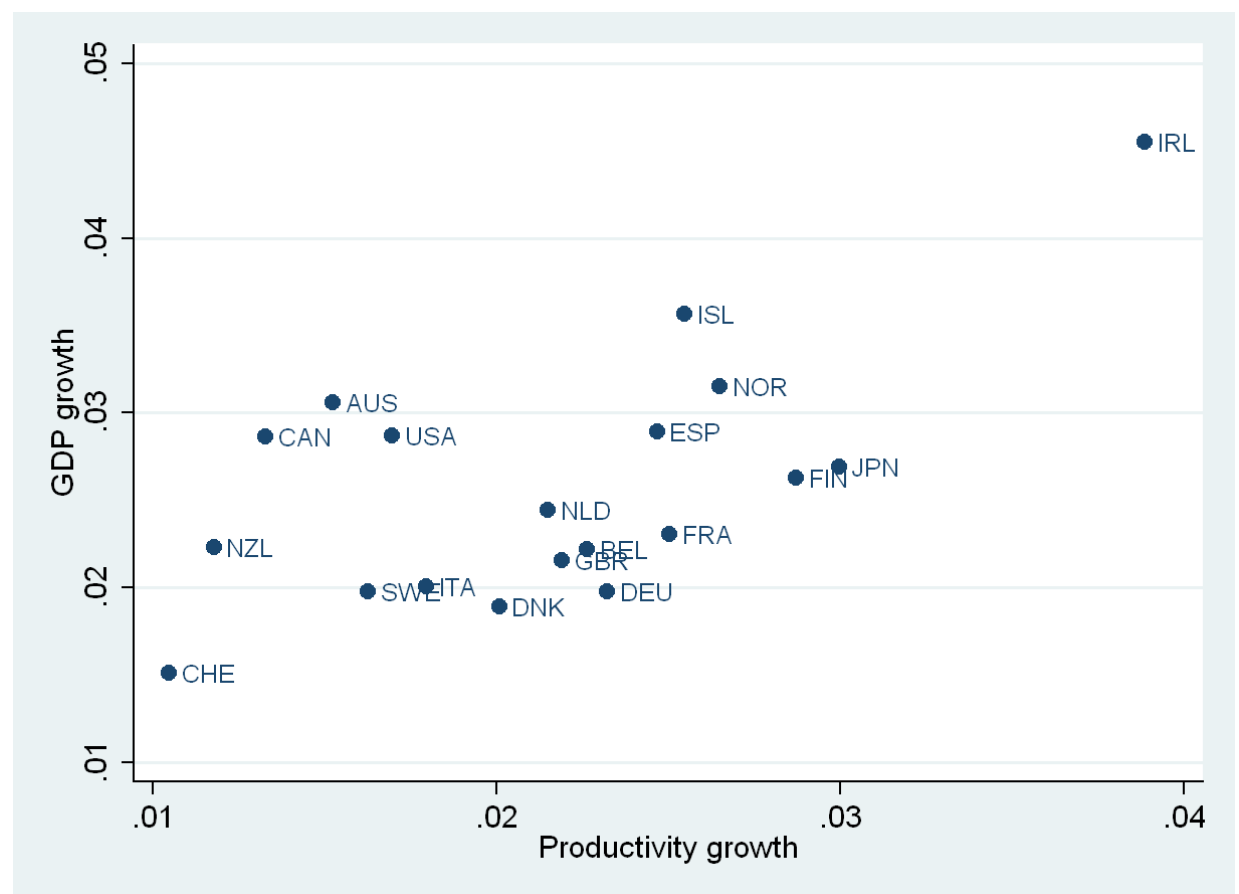

Figure 4: Relation between GDP growth and productivity growth for 1970 to 2009. Source: OECD, authors calculation. 
A.3 Tables 


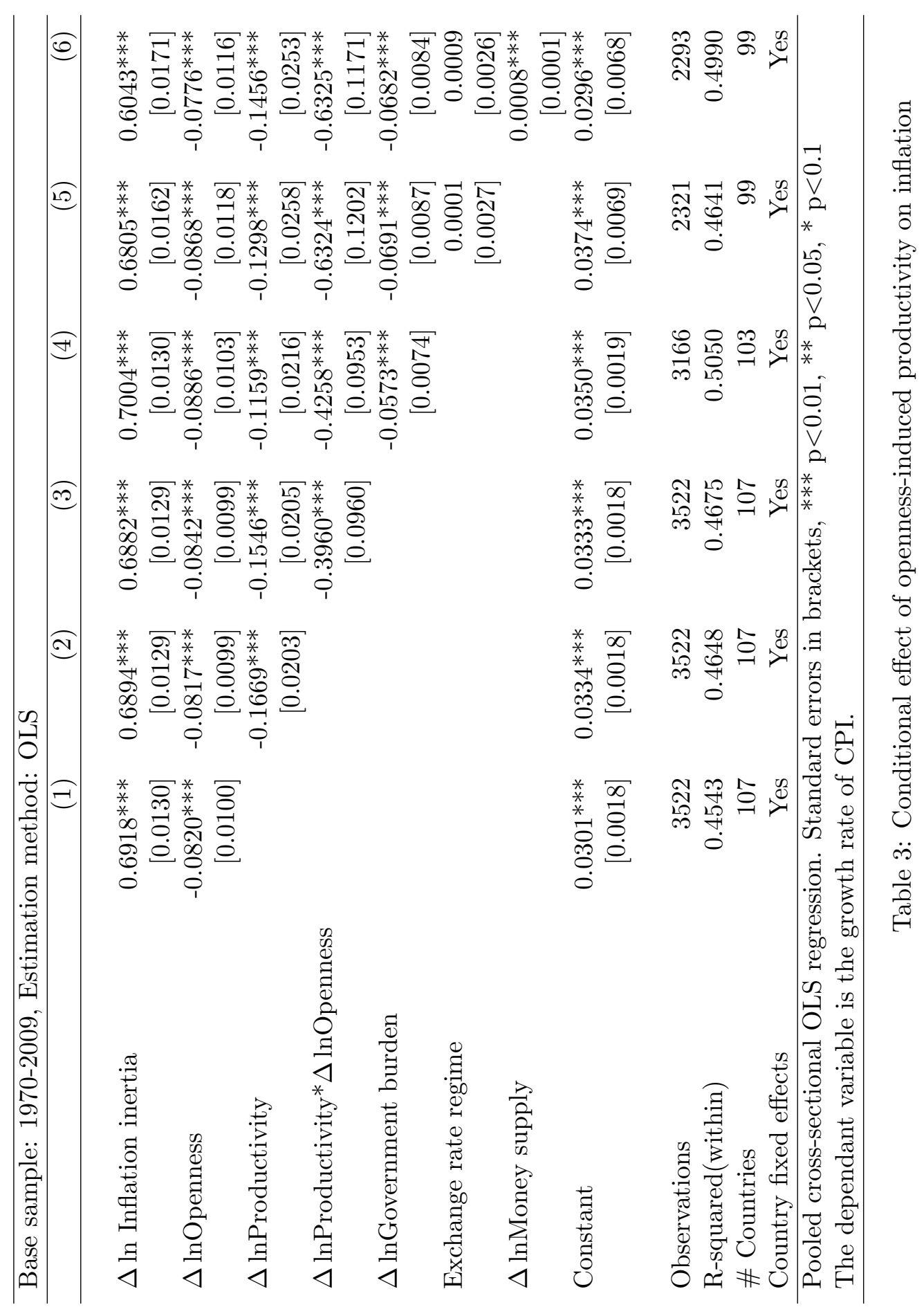




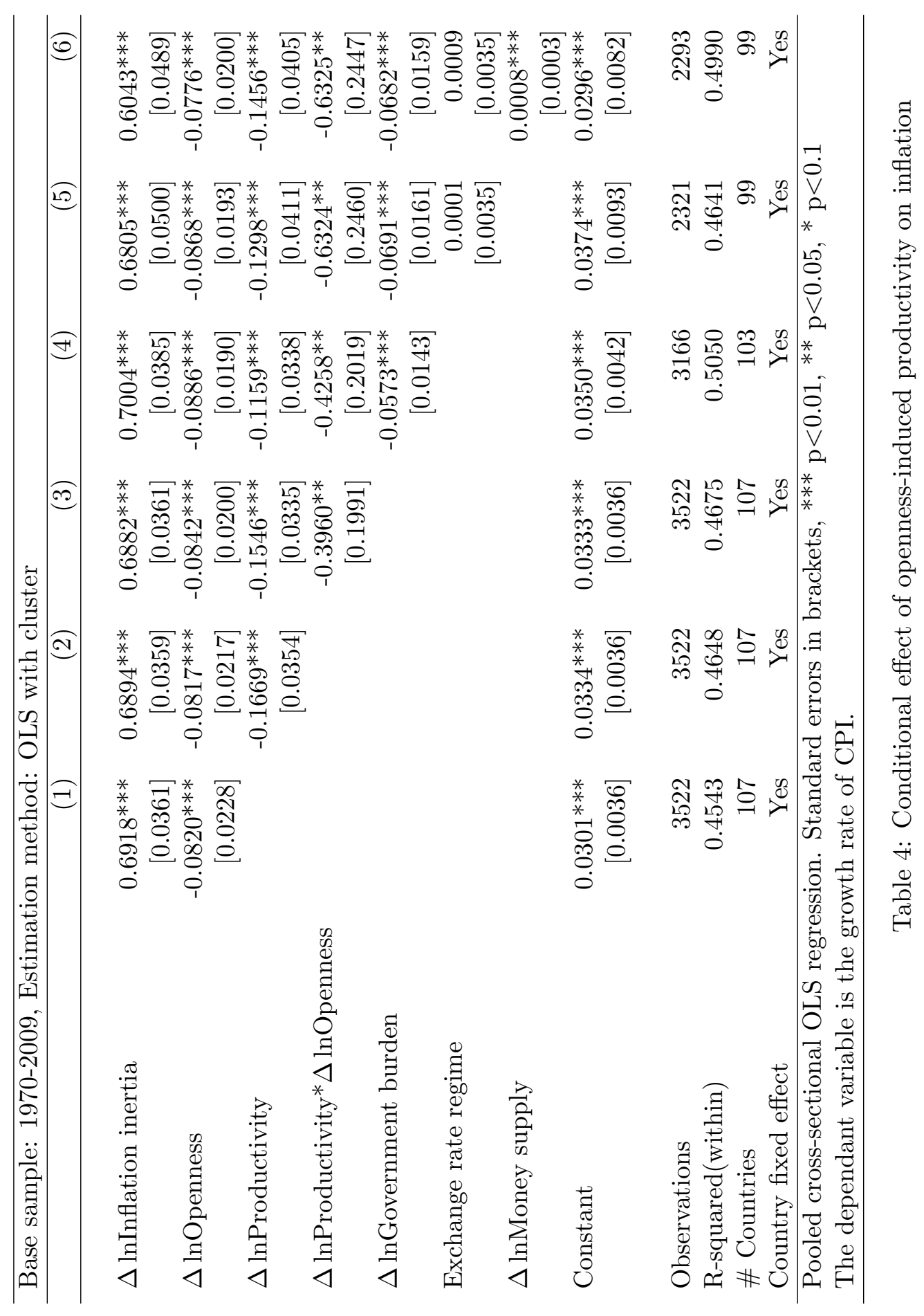




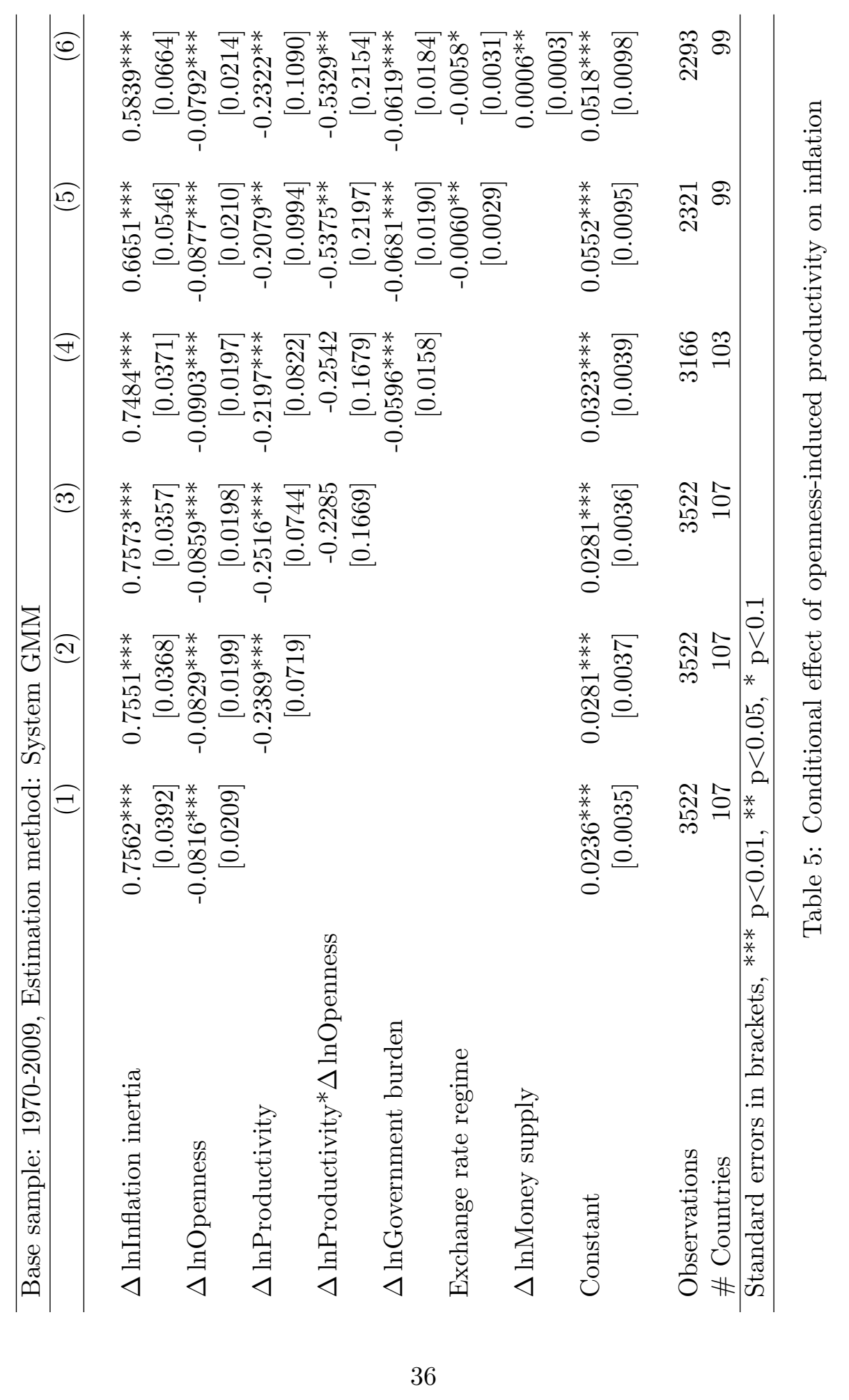




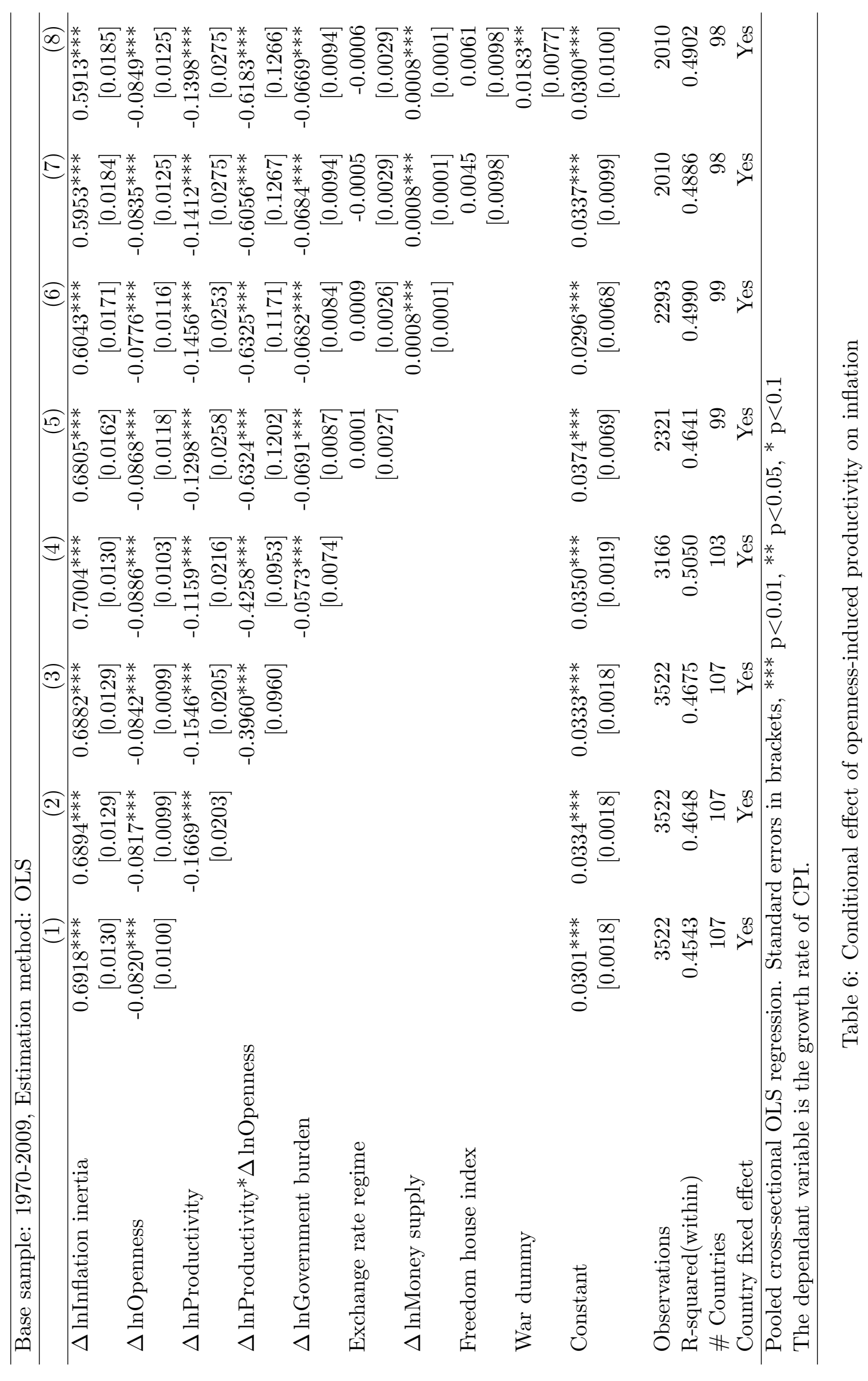




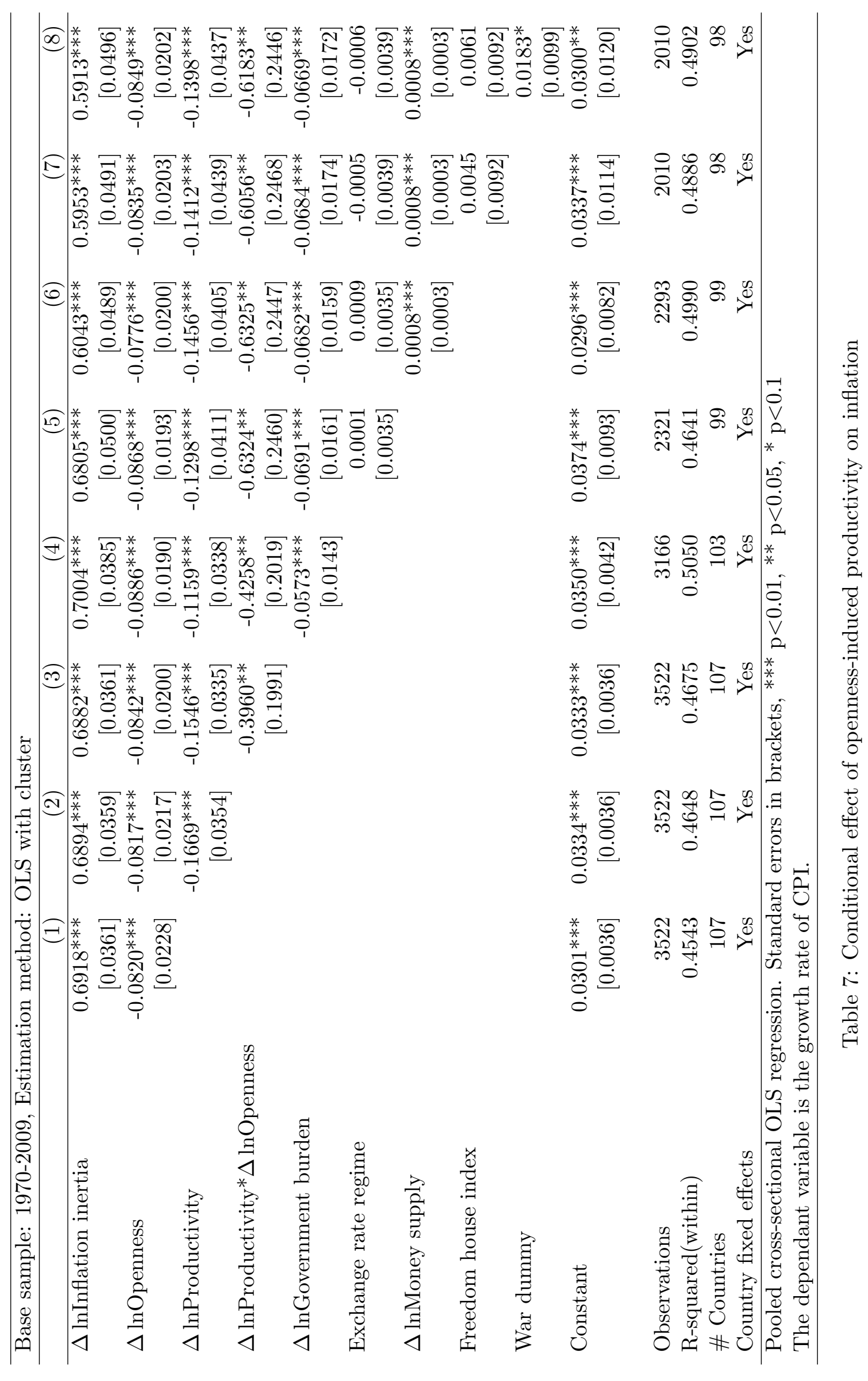




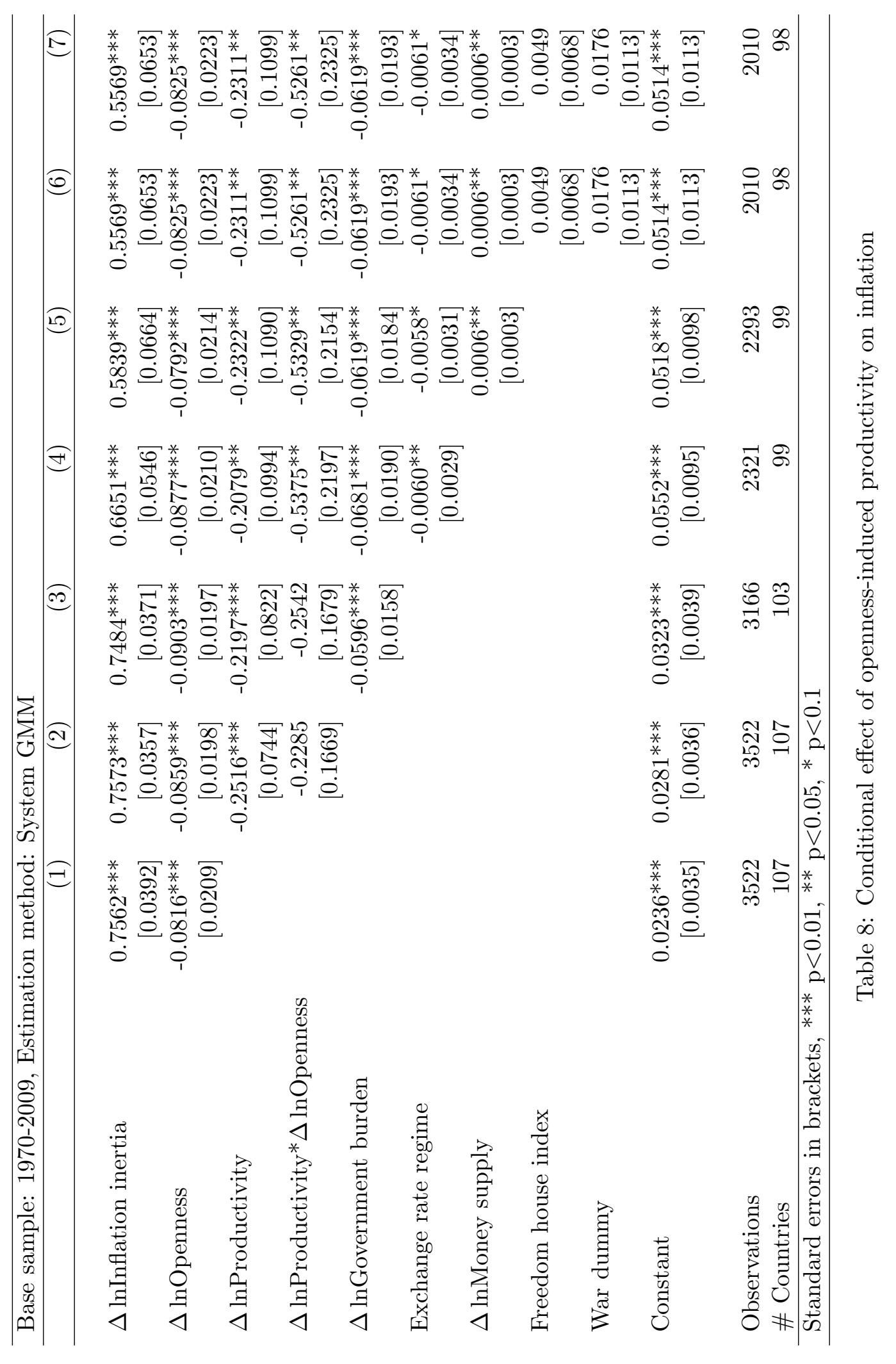




\begin{tabular}{lccccc} 
Variables & Obs & Mean & Std. Dev. & Min & Max \\
\hline$\Delta \ln$ Inflation & 3881 & .0985295 & .1199443 & -.2443037 & 1.237072 \\
$\Delta \ln$ Openness & 3942 & .0124337 & .1344365 & -1.416514 & 2.233043 \\
$\Delta \ln$ Productivity & 3944 & .0177307 & .0685903 & -.9773251 & .7804412 \\
$\Delta \ln$ Openness x & 3942 & .0002177 & .0158224 & -.2991453 & .3107563 \\
$\Delta \ln$ Productivity & & & & & \\
$\Delta \ln$ Govern burden & 3567 & .0794616 & .1776593 & -1.320454 & 1.469214 \\
$\Delta \ln$ Money supply & 4003 & 18.3786 & 27.69991 & -100 & 871.989 \\
Exchange regime & 2708 & 2.434269 & .807542 & 1 & 3 \\
Freedom house & 3108 & .5148005 & .3596953 & 0 & 1 \\
War dummy & 4164 & .1721902 & .377591 & 0 & 1 \\
\hline
\end{tabular}

Table 9: Summary Statistics

Algeria, Australia, Bahamas, Bahrain, Bangladesh, Barbados, Belize, Bhutan, Botswana, Burkina Faso, Burundi, Cameroon, Canada, Cape Verde, Central African Republic, Chad, China, Colombia, Congo, Rep., Costa Rica, Cote d'Ivoire, Cyprus, Denmark, Dominica, Dominican Republic, Ecuador, Egypt, Arab Rep., El Salvador, Equatorial Guinea, Ethiopia, Fiji, Gabon, Gambia, The, Ghana, Grenada, Guatemala, Haiti, Honduras, Hungary, Iceland, India, Indonesia, Iran, Islamic Rep., Israel, Jamaica, Japan, Jordan, Kenya, Korea, Rep., Kuwait, Lesotho, Liberia, Libya, Macao SAR, China, Madagascar, Malawi, Malaysia, Mali, Malta, Mauritania, Mauritius, Mexico, Morocco, Mozambique, Myanmar, Nepal, New Zealand, Niger, Nigeria, Norway, Pakistan, Panama, Papua New Guinea, Paraguay, Philippines, Poland, Qatar, Rwanda, Samoa, Saudi Arabia, Senegal, Seychelles, Singapore, Solomon Islands, South Africa, Sri Lanka, St. Kitts and Nevis, St. Lucia, St. Vincent and the Grenadines, Sudan, Suriname, Swaziland, Sweden, Switzerland, Syrian Arab Republic, Tanzania, Thailand, Togo, Tonga, Trinidad and Tobago, Tunisia, Turkey, Uganda, United States, Uruguay, Vanuatu, Venezuela, Zambia

Table 10: List of Countries 